\title{
YABANCILAŞMA BAĞLAMINDA BİR "TUTUNAMAYAN" KAHRAMAN: BEYAZ MANTOLU ADAM
}

\author{
IN THE CONTEXT OF ALIENATION A “DISCONNECTED” HERO: THE MAN \\ IN WHITE COAT
}

\section{Sevgül TÜRKMENOĞLU ${ }^{1}$}

\section{$\ddot{O} \mathbf{z}$}

Oğuz Atay, Türk edebiyatında modern roman ve hikâye tarzının önemli temsilcilerinden biri olarak kabul edilir. Kimi eleştirmenler tarafından post modernist anlayışın ilk temsilcilerinden biri olarak da kabul edilir. Atay eserlerinde, modern dünyanın ve şehir hayatının yalnız, aidiyetsiz ve iletişimsiz insanlarına yer verir. Modern dünyanın içinde tutunmaya çalışan bireylerin hikâyesi onun eserlerinin temelini oluşturur. Atay, modern dünyanın içinde var olmaya çalışan insanın bunalımını ele alır. Eserlerindeki kahramanlar modernizmin doğurduğu metalaşmaya ve değersizleşmeye karşı çıkarlar. Atay’ın Beyaz Mantolu Adam hikâyesi de modernizmin topluma yabancılaştırdığı bir adamın yabancılaşma serüvenine yer verir. Mantolu adam aidiyetsiz, bulunduğu ortama yabancı ve en önemlisi de iletişimini kaybetmiş bir figürdür. Hikâye boyunca hiç konuşmaz. Toplumun kendisine dayattığı her şeye tepkisizce boyun ĕ̆er. Yabancılaşmaya tepkisini hiçbir şey söylememekle dile getirir. Bu çalışmada Oğuz Atay’ın Beyaz Mantolu Adam hikâyesi yabancılaşma kavramı üzerinden değerlendirilmiştir. Hikâyenin kahramanı olan mantolu adam üzerinden yalnızlık, aidiyetisizlik, iletişimsizlik gibi kavramlar ele alınmıştır. Modernizmin getirdiği yabancılaşma ve toplumdan uzaklaşma halinin Beyaz Mantolu Adam hikâyesindeki işlenişi değerlendirilmiştir.

Anahtar Kelimeler: Oğuz Atay, Beyaz Mantolu Adam, modernizm, yabancılaşma, hikâye

\begin{abstract}
Oğuz Atay is considered as one of the important representatives of modern novel and story style in Turkish literature. He is also considered by some critics as one of the first representatives of post-modernist understanding. Atay's works include the lonely, unfaithful and non-communicative people of the modern world and city life. The story of the individuals who try to cling to the modern world is the basis of his works. Atay discusses the depression of the people who are trying to exist in the modern world. The heroes in his works oppose the commodification and insignificancy which is caused by modernism. The Man in White Coat story includes a man's adventure who is alienated by modernism to society, too. Man has no sense of belonging and most importantly loses communication. He never speaks during the story and obeys societal assertiveness without reaction. He expresses his reaction to alienation not saying anything. In this study, the story of Oğuz Atay's The Man in White Coat will be evaluated through the concept of alienation, no sense of belonging and uncommunicativeness. The alienation which is brought by modernism and the alienation state from the society will be evaluated in the story of The Man in White Coat.
\end{abstract}

Keywords: Oguz Atay, The Man in White Coat, modernism, alienation, story.

\footnotetext{
${ }^{1}$ Doç.Dr., Van Yüzüncü Yıl Üniversitesi Eğitim Fakültesi Türk Dili ve Edebiyatı Eğitimi Bölümü, se cabaz@hotmail.com, Orcid:0000-0002-1704-8014
} 


\section{Giriş}

Türk edebiyatının önemli yazarlarından olan Oğuz Atay (1934-1977), Kastamonu'da dünyaya gelir. Babası hukukçu ve bir süre CHP milletvekilliği yapmış olan Mehmet Cemil Atay, annesi Muazzez Zeki Hanım'dır. 1951 yılında TED Ankara Koleji'nden mezun olur. İstanbul Teknik Üniversitesi İnşaat Fakültesi'ni bitirir. 1957 yılında yedek subay olarak askerliğini yapar. Askerliğinin ilk altı ayını İstanbul'da, diğer kısmını Ankara'da tamamlar. Ankara'da kaldığı süre içinde Pazar Postası dergisinde yazan genç yazarlarla tanışır. 1959 yılında İstanbul' döner. 1959-1962 yılları arasında Denizcilik Bankası İstanbul Şehir Hatları İşletmesi'nde çalışır. 1961 yılında evlenip, 1967'de eşinden ayrılır. 1971-1973 yılları arasında Meydan Larousse Ansiklopedisi'nde redaksiyon işleri yapar. 1973 yılında Hürriyet Gazetesi'nin yayını olan Türkiye 1923-1973 Ansiklopedisi için madde yazarlığı yapar. 1974 yılında ikinci evliliğini yapar. 1975 yılında doçent olur. 1976 yılında beyninde çıkan tümör nedeniyle Londra'da bir tedavi süreci geçirir. Ancak bu hastalıktan kurtulamaz. 1977 yılında hayata gözlerini yumar.

\section{Eserleri:}

Roman: Tutunamayanlar (1971-1972), Tehlikeli Oyunlar (1973), Bir Bilim Adamının Romanı (1975), Eylembilim (1998).

Öykü: Korkuyu Beklerken (1995).

Oyun: Oyunlarla Yaşayanlar (1985)

Günlük: Günlük (1970-1977 yılları arasında tuttuğu günlükler) (1987)

Oğuz Atay, Türk edebiyatında modern ile post modern arasında konumlandırılan, modernist ve post-modernist anlayışta eserlerin öncü isimlerindendir. Atay'ın bu çalışmada ele aldığımız hikâyesinin de yer aldığı Korkuyu Beklerken ${ }^{2}$ kitabındaki bütün hikâyelerde aidiyetsizlik, yabancılaşma gibi kavramlar öne çıkar. Bu hikâyelerden biri olan Beyaz Mantolu Adam hikâyesi de yabancılaşma kavramının en fazla işlendiği hikâyelerden biridir.

\section{Yabancılaşma Kavramı ve Türk Edebiyatında Yabancılaşma}

Yabancılaşma kavramı İngilizceye Latinceden geçmiş olan alienation kelimesinden gelir. Alienato, "esrime, kendinden geçme benliğin dişına çıkma" (Demirer ve Özbudun, 1998:10) anlamlarındadır. Türk Dil Kurumu sözlüğünde yabancılaşma: "Belli tarihsel koşullarda insan ve toplum etkinlikleri ürünlerinin (emeğin, paranın, toplumsal ilişki sonuçlarının, insanın özelliklerinin ve yeteneklerinin) bu etkinliklerden bağımsız ve bunlara egemen ya da özlerinde olduklarından değişik biçimde kavranması" (Canpolat, 1983:1263) ifadeleriyle tanımlanır. Ahmet Cevizci, yabancılaşma kavramını maddeler halinde şu şekilde tanımlar:

“1. Özgün anlamı içinde, bir şeyi ya da kimseyi başka bir şeyden ya da kimseden uzaklaştıran, başka bir şeye ya da kimseye yabancı hale getiren eylem ya da gelişme.

2. Psikiyatride, normalden sapma durumu.

3. Çağdaş psikoloji ya da sosyolojide, kişinin kendisine, içinde yaşadığı topluma, doğaya ve başka insanlara karşı duyduğu yabancılık hissi.

4. Felsefede, şeylerin, nesnelerin bilinç için yabanc1, uzak ve ilgisiz görünmesi, daha önceden ilgi duyulan şeylere, dostluk ilişkisi içinde bulunulan insanlara karşı kayıtsız kalma, ilgi duymama, hatta bıkkınlık ya da tiksinti hissetme.

\footnotetext{
${ }^{2}$ Oğuz Atay, Korkuyu Beklerken, İletişim Yayınları, İstanbul, 1999. (Çalışmada kullanılacak alıntılarda verilen sayfa numaraları bu baskıya aittir.)
} 
5. Benin kendi özünden uzaklaşmasıyla, kendisine ve eylemlerine nesnel bir biçimde, sanki bir ustanın elinden çıkmış bir nesneye bakarcasına yaklaşımıyla belirlenen bilinç hali. Kişinin kendi benliğiyle ya da zihin halleriyle, kendisi arasına duygusal bakımdan mesafe bırakması durumu, kişinin gerçek beniyle olan içsel temasını yitirdiğini anlamasının sonucu olan kendisinden kopması hali..." (Cevizci, 2000:994)

$\mathrm{Bu}$ değerlendirmeden anlaşıldığı üzere yabancılaşma, kişinin kendi benliğinden ve toplumdan uzaklaşması, kısacası hem kendine, hem çevresine yabancılaşmasıdır. Yabancılaşma kavramının felsefe tarihinde Hegel ile beraber ortaya çıktığı kabul edilir. Hegel'e göre insanlık tarihi aynı zamanda insanoğlunun da yabancılaşmasının tarihidir. (Tolan, 1980:145). İsmet Özel, Hegel'in, ruhun ideal bir varlık olarak kendini gerçekleştirme gayretleri içinde olmasına rağmen bu hedefini kendi gözünden sakladığını, böylece ruhun gerçek yönelimi ile $\mathrm{o}$ anda yapmakta olduğunun birbirine yabancı kaldığını ve bu yabancılaşmadan tatmin ve gurur duyduğunu belirttiğini söyler. (Özel, 2013:71)

Yabancılaşmanın psikolojik, sosyolojik, siyasal, felsefi anlam içerdiğine işaret eden Barlas Tolan, bu kavramın aynı zamanda içinde bir isyan barındırdığını şu ifadelerle dile getirir:

"İnsanın kendi özünden, ürününden, doğal ve toplumsal çevresinden koparak onların egemenliği altına girmesi şeklinde tanımlanabilecek yabancılaşma kavramı, aynı zamanda sosyal bilimlerde bir moda olduğu kadar, insanı makinalaştıran, metalaştıran ve sonunda köleleştiren rasyonalist ve teknokratik bir uygarlık biçimine karşı oluşan başkaldırının bir simgesi haline gelmiştir" (Tolan, 1980:4).

Topluma yabancılaşma, bireyin çeşitli nedenlerle toplum dışına itilmesi, ya da bireyin kendini toplumun dışında hissetmesidir. (Baş, 2003:26) Marx’a göre insanın emek vererek ürettiği mal, emeğin önüne geçtiğinde insan, varlığına karşı yabancılaşır. Eşyanın fetiş haline gelmesi ve özneleşmesiyle insan/ işçi kendi türüne yabancılaşarak yalnızlaşır. (Marx, 201:22).

Jameson'a göre modernist yapıtlar, eski Marksizm'in ileri süreceği gibi bizi gerçeklikten uzaklaştırma, onun yerine lüzumsuz kaygılar geçirme ve dekadan değer ve faaliyetleri teşvik etme yollarından ibaret değildirler. Bu yapıtlar, gerçekliği çarpıtma ve bastırma yollarıdır. Devrimci sanatın içeriğinden farklı bir şeyden söz etmezler. Onlarda da aynı korku ve kaygılar vardır. Aradaki fark, modernizmin bu kaygıları ifade etmek yerine idare etmeye, gizlemeye ve yeraltına itmeye çalışmasıdır. ( Jameson, 2005:254).

Ecevit ( 2004:39), “yabancılaşma estetiği somut görüntüyü yabancılaştırarak yeniden kurgularken özde gerçekçilikten uzaklaşmaz; görünürde alışık olduğumuz, bize yabancı olmayan bir dünyanın özünde yatan kaotik çelişkileri, belirsizliği, anlaşılmazlığı gözler önüne serer. Bu nedenle de çağın insana yabancı gerçekliğiyle örtüşür” ifadeleriyle yabancılaşmanın mevcut düzendeki çelişkileri ortaya çıkarıp görünür kıldığına dikkat çeker.

Yabancılaşmaya sosyolojik bir pencereden bakan Simmel (2009:30), yabancılaşmanın özellikle metropollerde gelişen bir olgu olduğuna dikkat çekerek metropolün, kişisel olan her şeyi yutarak büyüyen, yabancılaşmanın bütün çıplaklığıyla sergilendiği bir sahne olduğunu belirtir. Binalarda, eğitim kurumlarında, tüm mekânlara hâkim olan teknolojinin yarattığı harikalarda, sunduğu nimetlerde, topluluk hayatı oluşumlarında, gözle görülür devlet kurumlarında, dayanılmaz ölçüde billurlaşmış ve gayri şahsileşmiş bir tin söz konusudur. Kişilik, bunun etkisi altında kendini idame ettiremez.

Yabancılaşma ile ilgili yukarıdaki tespitler birbiriyle örtüşürken İsmet Özel bu kavrama farklı bir açıdan bakar. Özel'e göre, (2013:71) çağa yabancı olmak çağdan bîhaber olmak anlamına gelmez. "Tam tersine çağ hakikate yabancı kaldığı için hakikat adına yola çıkanlar çağın bir unsuru olmayı reddederler ve çağa onun tanımadığı doğruları getirirler.” 
Yabancılaşma hakkındaki bütün bu değerlendirmeler neticesinde varılan nokta, yabancılaşmanın modern dünyanın içinde var olmaya çalışan bireyi metalaştırdığıdır. Kendine ve çevresine yabancılaşan birey, bir aidiyetsizlik hissi yaşar. Bunun neticesinde bulunduğu ortama, çevreye, kişilere karşı hissiz ve tepkisiz bir varlığa dönüşür.

Türk edebiyatında modernizmin ortaya çıkması batıdan çok sonra gerçekleşir. 19. yüzyıl ile birlikte realizm, yerini modern edebiyata bırakır. Tanzimat ile birlikte Türk edebiyatına giren roman ve hikâye gibi türlerin ilk örneklerinde dönemin toplum yapısına ve geleneksel anlayışına bağlı kalınmıştır. Batı edebiyatında roman ve hikâye bu yüzyılda daha bireysel konulara eğilip, bireyi ön plana çıkarırken Türk toplumunun gelenekçi yapısı henüz roman ve hikâye gibi türlerde bu konuları işleyecek zemine sahip değildir. Murat Belge Türk edebiyatında modernist anlayışın batıdan daha geç olmasını iki toplum arasındaki sosyal farklılığa bağlar:

"Batı romanı ya da romancısı, bireylerin iç dünyalarını, gizli duygularını anlatırken gözlerinin önünde bir hayli zenginleşmiş bir içsel hayat vardı. Onlar, romancıya özgü bir ayrıcalık olan kişilere içlerinden bakma yöntemini bu kadar geliştirdilerse bunun bir nedeni de bakabilecekleri karmaşık içsel yaşantılar olmasıydı. Türk romancısının bu alanda karşılaştığı handikap bu içsel dünyanın yetersizliğidir" (Belge, 1998:38).

İlk örnekleri daha çok didaktik özellikler gösteren hikâye ve romanlar "topluma öğretmenlik yapma, onu eğitme amacı taşımaktaydı." (Yürek, 2005:46). 20. Yüzyıla gelindiğinde Türk roman ve hikâyesinde modernist anlayışın ilk örnekleri için zemin uygun hale gelir. Modernist roman ve hikâyenin birey merkezli anlayışına paralel bir biçimde değişen toplum yapısı modern hikâye ve roman için müsait bir ortamdır. Büyük şehrin insanı yalnızlaştırması, müstakil geniş evlerden ve kalabalık aile ortamından apartman hayatına geçiş gibi toplumsal durumların da etkilediği modernizm, edebiyatta bireyin yabancılaşması ve aidiyetsizlik hisleri üzerinden ilerler.

Oğuz Atay, "Türk romanının geleneksel çizgisinden çıkarak başka tür bir romanı deneyen ilk Türk yazarı[dır]" (Moran, 1997:197). Hikâyede de aynı tavrı sürdüren Atay, modern ile post modern arasında bir yerde konumlandırılan bir yazar olarak 20. yüzyılın bunalımlarını eserlerinde öne çıkaran, bireyin yalnızlığına, aidiyetsizliğine ve topluma uyum sağlayamama psikolojisine yer veren anlatılarıyla dikkat çeker. Yazarın Tutunamayanlar romanı, adından itibaren bir tutunamama, ait olamama, öteki olma durumunu anlatır. Oğuz Atay, Tutunamayanlar'ı yazdığı 1968 yılında "Türk edebiyatında o güne değin birkaç kez hafifçe aralanmasına karşın kimsenin açmadığı bir kapıyı ardına kadar açtığının bilincindedir." (Ecevit, 2005:232). Bu kapı, modernizm anlayışına açılan kapıdır. "Zamansal art ardalığın montaj kalıplarıyla delindiği, iç ve dış dünyalar arasındaki sınırların silindiği, farklı ontolojilerdeki gerçekliklerin farklı biçim ve anlatım ögeleri aracılığıyla çok katmanlı bir yapı içinde verildiği bir romandır «Tutunamayanlar»" (Ecevit, 2004:86).

Tutunamayanlar romanında modern insanın yabancılığını ve aidiyetsizliğini alışılmışın dışında bir anlayışla ele alan Atay, bu alışılmışın dışındaki tarzını hikâyelerinde de sürdürerek modern dünyanın mensubu şehirli insanın huzursuzluğunu, yalnızlığını, yabancılaşmasını ele alır.

\section{Beyaz Mantolu Adam Hikâyesinde Yabancılaşma}

Oğuz Atay'ın Beyaz Mantolu Adam hikâyesi yabancılaşmış, soyutlanmış ve tepkisizleşmiş insanı ele alır. Yıldız Ecevit, Oğuz Atay'ın Beyaz Mantolu Adam karakterini oluştururken Çiçek Pasajı'nda kemer satan bir adamdan esinlendiğini söyler. Saçı sakalı birbirine karışmış yarı meczup garip bir adam" (Ecevit, 2005:478) olan kemer satıcısı Atay'1 oldukça etkilemiştir. Atay’ın, yakın çevresi yazarın "sistemin dışında kalan, düzene 
tutunamama olgusunu uçta yaşayan insanlara: berduşlara, çöpleri karıştıranlara... özel bir ilgi duyduğunu" (Ecevit, 2005 479) söylerler. Beyaz Mantolu Adam hikâyesi, anlatı boyunca hiç konuşmayan, hiçbir olaya tepki vermeyen bir adamın anlatılmasıyla başlar. Adam, bir meydanda dilenmektedir. Hiç konuşmaz, diğer dilencilerin yaptı̆̆ 1 gibi kendini acındırmaz. Hikâye boyunca hep geniş alanlarda, topluluk içinde bulunan adam çevresindeki her şeyden uzak, âdeta soyutlanmış gibidir. Hikâyenin başından sonuna kadar adamın bu durumu değişmez. Hikâyenin sonunda ise üzerindeki beyaz renkte kadın mantosunun iyice tuhaflaştırdığı görüntüsüyle arkasında büyük ve meraklı bir kalabalık olduğu halde denize doğru yürür. Suyun içinde gözden kaybolur.

Hikâyenin en dikkat çekici noktası odağa alınan adamın içinde bulunduğu ortam ve topluluktan olabildiğince soyutlanıp aykırı ve ötekileştirilmiş bir birey olarak okuyucunun dikkatine sunulmasıdır. "Kloş etekli beyaz ve uzun bir kadın mantosunun içinde dolaşan, hiç konuşmayan, ayrıksı görünümlü groteks adam ile karşısında tek bir organizmaymışçasına devinerek onu kullanan farklı bir evrenin insanları Atay'ın metninde oluşturmaya çalıştığı bu odak imgenin iki ana yapı taşıdır" (Ecevit, 2005:477). Adamın hikâyede ayrıksı görünümüyle öne çıkması tesadüfi değildir. Yazarın amacı zaten onun bu yabancılaşmış ve toplumdan soyutlanmış durumuna dikkat çekmektir. Hikâyede kahramanın diş görünüşü net değildir. Hiçbir fiziksel özelliğinin tasvirine rastlanmaz. Kalabalıklar içinde yer alması onun aidiyetsizliğini belirginleştirir. "Kalabalık bir topluluk içindeydi" (s.11) ifadesi ile ilk önce adamın mekânı belirlenir. Ardından gelen cümlelerde şekillendirilmeye başlayan adam, acziyetiyle öne çıkarılır: "Başarısızdı. Parası yoktu. Dileniyordu" (s.11). Atay'ın tasvir ettiği adam, okuyucuda bir acıma duygusu uyandırmadan verilir. Nurdan Gürbilek, yazarın Tutunamayanlar romanında da bu tavrı takındığına dikkat çeker ve Atay'ın Tutunamayanlar romanında yalnız yoksulluktan değil, aşağılanmışlıktan, başkaları tarafından küçük görülüyor olmaktan da söz ettiğini vurgular ( $2007: 10)$.

Ancak bu duygular, acıma hissi katılmadan verilir. Benzer biçimde adam da hikâyenin başında okuyucuda herhangi bir acıma hissi uyandırılmadan anlatılır. Daha çok başarısızlığ öne çıkarılır. Bir cami önünde dilenirken etraftakiler, sağlam olduğu halde dilendiği için onu kınarlar. Adam çalışma teşebbüsünde bulunsa da bunda da başarı elde edemez:

"Sağlam adamsın; utanmıyor musun dilenmeye?" şişman bir adam duruyordu yanı başında: "Bir iş verilse çalışmazsın." Şişmanın yerde duran bavuluna baktı, iki eliyle tutup kaldırmaya çalıştı yükü; başaramadı. Sonra bir hamal gördü uzakta, becerikli. Onun gibi yaptı: çömelerek sırtını bavula dayadı, sapı kavradı; olmadı” (s.13).

Yazar, hikâyenin ilk cümlesinde kalabalık topluluğun içindeki adamı başarısızlıkla itham ederken yalnızca maddi anlamda bir başarısızlığı kastetmez; kalabalıklara uyum sağlayamayan, aidiyet hissini kaybetmiş kahramanın yalnızlığı da bir tür başarısızlıktır. Adam, bulunduğu muhite yabancıdır. Yazar, adamın dış görünüşünü tasvir ederken bile bir tesadüf sonucu görülmüş bir görüntüymüş gibi anlatır. Adam, sokakta yürürken bir boy aynasının önünden geçer ve aynadaki görüntüsü ile çok kısa bir an göz göze gelir. Bu ayna, okuyucunun zihninde belli belirsiz var olan ve diş görünüşü hiç tasvir edilmeyen karakteri hızlı bir şekilde anlık bir görüntüyle gösterir. Bu aynadaki görüntü o kadar hızlı belirip kaybolur ki, adamın dış tasviri eksik kalır:

“(...) Yorgun ve terli iki hamalın ortasında duran oymalı, yaldızlı büyük bir boy aynasında kendini seyretti: Ceketi yoktu, gömleği parça parçaydı. İstemeyerek iki serserinin kavgasına karıştığı, onlara aracılık ettiği bir sırada yırtılmış olan gömleğinin parçalarını üst üste getirdi aynaya bakarak; pantolonunu tutan ipi çözdü, daha sıkı bir dügüum attı. Sonra aynayı götürdüler; yırtık pantolonunu ve çorapsız ayaklarına geçirmiş olduğu lastikleri seyredemedi."(s.14) 
Yabancılaşma, adamın bir eskicide beyaz bir kadın mantosu ile karşılaşıp onu alması ve giymesiyle üst seviyeye çıkar. Burada dikkate değer nokta, adamın mantoyla karşılaşmasıdır. Hikâye boyunca tepkisiz oluşuyla öne çıkan adamın bu durumu mantoyla karşılaşmasında da devam eder. Adam mantoyu bulmaz, manto gelip onu bulur:

“(...) Nereye asıldıkları belli olmayan elbiselerin ve kumaşların arasına sıkıştı; durmak zorunda kaldı. Rüzgârın ya da gelip geçenlerin salladığ 1 beyaz bir manto süründü yüzüne. Uzun ve aydınlık bir manto. Kloş etekli, kocaman düğmeli bir hayalet; geniş yakalı, serin." (s.14)

Adamın yabancılaştırılıp öteki konumunda görüldüğü kısımlardan biri de mantoyu alıp giymek istemesinin satıcı ve çevredekiler tarafından tuhaf karşılanmasıyla başlar. Adam, çevresindekilerin bakışına göre hem gülünç, hem de aykırıdır:

"Manto vücuduna yapıştı. Satıcı hızla çevirdi onu; etekler dönerek açıldı. Meyhanedeki adam bu kadarını beklemiyordu; birden gülmek zorunda kaldığı için ağzındaki bütün birayı ileri püskürttü. Satıcı kendine geldi: "Kadın mantosu bu, hemşerim; sana olmaz." Mantoyu aceleyle çıkarmak istedi müşterinin üzerinden”. (s.15).

Adam, beyaz mantosuyla sokaklarda ilerlerken artık Beyaz Mantolu Adam'dır. Yabancısı olduğu mekâna ve kalabalığa olan mesafesi daha da artmış ve giydiği beyaz kadın mantosu ile daha da aykırı bir görünüme bürünmüştür. Dikkatleri üzerine çeken mantosuyla çevresindekiler için yalnızca ilginç, seyirlik bir nesnedir:

“Beyaz mantosuyla kalabalığa karıștı. Tentelerin bittiği yerde gökyüzüne baktı. Yerdeki bir su birikintisinden güneşle birlikte yansıdı. Sonra su birikintisi kalabalıklaştı; lekesiz görüntüsünü irili ufaklı gölgeler çevirdi. Mantosunu seyretmek için eğilince, henüz şaşkınlığ geçmemiş ve onu nasıl karşılamak gerektiğini bilemeyen topluluğu gördü suyun içinde. Mantosunun eteklerini kirletmemek için su birikintisinin çevresinden dolaştı. Onu doğrudan doğruya izlemek isteyenler suyu geçmeye çalışırken islanarak yan yolda kaldılar.” (s.16)

Beyaz manto, alay konusu olur ve hikâye boyunca küçümseme ve yok sayılma gibi durumlarla öne çıkan adam, mantoyu giydikten sonra daha da küçümsenen bir figüre dönüşür. Beyaz Mantolu Adam, küçümsenmesiyle Gogol'ün Palto kitabındaki Akaki Akakiyeviç'i anımsatır. Atay, Günlük adlı eserinde Palto'dan etkilendiğini, bu eserin “derinden sarsa[n]"bir yönü olduğunu söyler(Atay, 130). Palto'nun kahramanı Akaki Akakiyeviç küçük bir memurdur ve işyerindeki arkadaşları tarafından küçümsenen, değersiz bir kişi olarak öne çıkar. O da başarısız ve tutunamamış bir karakterdir. Akaki Akakiyeviç'in de öne çıkan nesnesi paltosudur. Bu eski palto "memurların eğlencesi” (Gogol, 1999: 89) olmuştur. Beyaz Mantolu Adam da Akaki Akakiyeviç gibi çevresindeki insanlar için bir eğlence malzemesi olur.

Beyaz Mantolu Adam'ın bir mağazanın sahipleri tarafından alınıp vitrine canlı manken olarak konulması ve bir pazarlama aracı olarak kullanılması öyküdeki grotesk unsurlardan biri olmasının yanı sıra, mantolu adamın tepkisizliğine ve çevresi tarafından metalaşmış bir varlık gibi görülmesine gönderme olarak okunabilir. Beyaz Mantolu Adam'ın vitrindeki duruş pozisyonu: "naylon iplerle tavana asmaya karar verdiler sonunda kolları. Bir kolu ileri uzattılar, bağladılar ve ipi vitrinin üstündeki bir çiviye tutturdular. Öteki kolu da duvarda boşalttıkları bir rafa yerleştirdiler." (s.19) şeklinde tasvir edilir. Vitrindeki bu duruş şekli çarmıha gerilmiş İsa görüntüsünü andırmaktadır. Hikâyenin ilerleyen bölümlerinde mağazadan ayrıldıktan sonra sokaklarda dolaşan Beyaz Mantolu Adam, geniş bir meydana gelip güvercinler için mısır alır ve "kollarını iki yana açarak" (s.22) mısırı güvercinlere serptiğinde çevredekilerin ağzından çarmıh kelimesi açıkça söylenir: 
"Parkın girişindeki duvarın üstünde oturan kasketli bir genç, yanındakine, «put gibi olmuş, şuna bak» dedi. «Çarmıh», diye düzeltti öteki. Güldüler. (s.22)

Oğuz Atay, benzer biçimde Tutunamayanlar romanında da İsa'dan, İncil'den yoğun bir biçimde söz eder. İsa metaforu sıkça kullanılır. Çünkü "İsa, tutunamayanların arketipidir." (Moran, 1997:212). O da içinde yaşadığı toplumun paralı, egemen sınıfına ve din adamlarına, onların değer yargılarına ters düşmüş, horlanmıştır. (Moran, 1997:212). Bu bağlamda İsa ve çarmı metaforlarının yabancılaşma, öteki olma gibi durumları temsil ettiğini söylemek mümkündür.

Yabancılaşmanın öne çıkarıldı̆̆ı kısımlardan biri de Beyaz Mantolu Adam'ın çevresindeki insanların onun hakkında konuştukları bölümdür. Beyaz Mantolu Adam, mağaza vitrininde canlı mankenlik yaparken kirli ayakları görünmesin diye beyaz kumaşlarla sarılır. Mağazadan ayrılırken bu kumaşları ayağından çıkarmadığı için meydanda da bu sargılar ayağındadır. Bunu gören kalabalık, mantolu adam için birtakım yorumlarda bulunur. $\mathrm{Bu}$ ifadelerde dikkat çeken bir ötekileştirme öne çıkar:

"Kalabalık arttı. «Ayakları sargı içinde.» «Cüzzamlı olmasın.» İtişerek çekildiler. Hiçbir şeyden korkmayan çocuklar, yani çocukların hepsi, eteklerini tutarak çevirdiler onu. «Karnına çengelli iğneler takmış». "Kollarına ipler bağlı.» «Sakın tımarhaneden kaçmış olmasın»" (s.23)

Beyaz Mantolu Adam kalabalık tarafından cüzzamlı veya deli olarak nitelendirilerek toplumun tamamen dışına itilir. Ayrıca meraklı bir kalabalık tarafından etrafının çevrilmesi, bir meta gibi izlenmesi de onun olabildiğince yabancılaştırıldığını ve kalabalığın dışında olduğunu göstermesi bakımından dikkate değer.

Beyaz Mantolu Adam'in, üzerindeki beyaz mantosuyla bir halk plajına girmesi grotesk bir yaklaşımdır. Kışlık bir manto ile dolaşması, mantonun beyaz renkte bir kadın mantosu olması, plaj ile mantonun yoğun tezadı Beyaz Mantolu Adam'ın kalabalığın içindeki ayrıksı duruşunu arttırır. Simmel yabancılaşmanın metropolle birlikte ortaya çıktığını belirterek, kişinin tanınma ve fark edilme ediminin elinden alındığına işaret eder. Kişi de fark edilmek için "kasıtlı bir şekilde tuhaf olmaya teşvik edilir; yani yapmacık tavırlar, ani değişiklikler gibi metropole özgü aşırılıklara yönelir” (Simmel, 2009:99). Beyaz Mantolu Adam'da da aykırı tavırlar onun giyim kuşam ve tepkisizliğiyle öne çıkar.

\section{Sonuç}

Beyaz Mantolu Adam yalnızlık, aidiyetsizlik iletişimsizlik kavramlarının beslediği yabancilaşma olgusu üzerine kurgulu bir hikâyedir. Yazar, hikâye boyunca çevresinden kopmuş bir insan üzerinden iletişimsizliği vurgular. Hikâyenin kahramanı olan adam, hikâye boyunca hem tepkisizliği, hem de silik yapısıyla hikâye içinde bir flaneur edasıyla dolaşır. Yalnızca etrafı gözlemekle yetinir. Hikâyeye nasıl sessiz bir şekilde girdiyse aynı sessiz ve tuhaf haliyle bir halk plajından denize doğru ilerler ve suyun içinde kaybolur. Bir bakıma intihar eder. Hikâyenin sonunda, yabancılaşmış bir karakter olan Beyaz Mantolu Adam'ın soyutlandığı dış dünyadan kendi kendini yok ederek ayrıldığını söylemek yanlış olmaz. Yazar, ayrıksı bir figür olarak bulunduğu toplumda tutunamayan Beyaz Mantolu Adam'a bu beklenmedik sonu uygun görerek hikâyeyi tuhaf bir finalle bitirirken, kalabalıktan biri "Amma da hikâye" der. Bu cümle hikâyenin son cümlesidir. Yazar bu cümleyle hem bir üst kurmaca yapar hem de hikâyenin sonunda grotesk bir tavır sergilemiş olur. Sonuç olarak bir adı bile olmayan Beyaz Mantolu Adam, bulunduğu zamanın ve mekânın bir parçası olmayı sessizliği ve tepkisizliğiyle reddeder. Hikâyeye nasıl sessizce girdiyse aynı sükûnetle ve iz bırakmadan hikâyeden ayrılır. 


\section{Kaynakça}

ATAY, O. (2005). Günlük. İstanbul: İletişim Yayınları.

ATAY, O. (1999). Korkuyu Beklerken. İstanbul: İletişim Yayınları.

BAŞ, S. (2003). Türk Hikâyeciliğinde Yabancılaşma (1950-1980). Yüzüncü Y11 Üniversitesi Sosyal Bilimler Enstitüsü, Türk Dili ve Edebiyatı Anabilim Dalı Yayımlanmamış Doktora Tezi.

BELGE, M. (1998). Edebiyat Üstüne Yazılar. İstanbul: İletişim Yayınları.

CANPOLAT, M. (1983). Türkçe Sözlük. Ankara: Türk Dil Kurumu Yayınları.

CEVİZĊ, A. (2000). Paradigma Felsefe Sözlüğü. İstanbul: Paradigma Yayınları.

DEMIRER, T.; ÖZBUDUN S. (1998). Yabancılaşma. Ankara: Öteki Yayınevi.

ECEVIT, Y. (2005). Oğuz Atay’ın Biyografik ve Kurmaca Dünyası. İstanbul: İletişim Yayınları.

ECEVIT, Y. (2004). Türk Romanında Postmodernist Açılımlar. İstanbul: İletişim Yayınları.

GOGOL(1999). Üç Öykü (Burun-Fayton-Palto). (Çev. Orhan Veli, Erol Güney). İstanbul: Çağdaş Matbaacilık.

GÜRBİLEK, N. (2007). Mağdurun Dili. İstanbul: Metis Yayınları.

JAMESON, F. (2005). Modernizm İdeolojisi. (Çev. Kemal Atakay, Tuncay Birkan). İstanbul: Metis Yayınları.

MORAN, B. (1997). Türk Romanına Eleştirel Bir Bakış 1. İstanbul: İletişim Yayınları.

SIMMEL, G. (2009). Modern Kültürde Çatışma.(Çev. Tanıl Bora-Nazire Kalaycı-Elçin Gen). İstanbul: İletişim Yayınları.

TOLAN, B. (1980). Çağdaş Toplumun Bunalımı: Anomi ve Yabancılaşma. Ankara İktisadi ve Ticari İlimler Akademisi Yayınları. Ankara: Kalite Matbaası.

ÖZEL, İ. (2013). Üç Mesele Teknik-Medeniyet- Yabancılaşma. İstanbul: Tiyo Yayınları.

YÜREK, H. (2005). Cumhuriyet Dönemi Türk Romanında Modernizmin Yeri. Mersin Üniversitesi Sosyal Bilimler Enstitüsü Türk Dili ve Edebiyatı Bölümü Yayımlanmamış Yüksek Lisans Tezi. 